American Journal of Applied Sciences 8 (1): 92-96, 2011

ISSN 1546-9239

(C) 2010 Science Publications

\title{
An Enhanced Russell Measure of Super-Efficiency for Ranking Efficient Units in Data Envelopment Analysis
}

\author{
${ }^{1,2}$ Ali Ashrafi, ${ }^{1,3}$ Azmi Bin Jaafar, ${ }^{1,4}$ Lai Soon Lee and ${ }^{1,4}$ Mohd Rizam Abu Bakar \\ ${ }^{1}$ Institute for Mathematical Research, Universiti Putra Malaysia, \\ 43400 UPM SERDANG, Selangor, Malaysia \\ ${ }^{2}$ Department of Mathematics, Faculty of Mathematics, Statistics and Computer Science, \\ University of Semnan, Semnan, Iran \\ ${ }^{3}$ Department of Information Systems, Faculty of Computer Science and Information Technology, \\ Universiti Putra Malaysia, 43400 UPM SERDANG, Selangor, Malaysia \\ ${ }^{4}$ Department of Mathematics, Faculty of Science, Universiti Putra Malaysia, \\ 43400 UPM SERDANG, Selangor, Malaysia
}

\begin{abstract}
Problem statement: Conventional Data Envelopment Analysis (DEA) helps decision makers to discriminate between efficient and inefficient Decision Making Units (DMUs). However, DEA does not provide more information about the efficient DMUs. Super-efficiency DEA model can be used in ranking the performance of efficient DMUs. Because of the possible infeasibility of radial super-efficiency DEA model, the ranking has been limited to the model under the assumption of Constant Returns to Scale (CRS). Approach: This study proposes a super-efficiency model based on the Enhanced Russell Measure (ERM) of efficiency. This is a non-radial measure and appropriate for ranking the efficient DMUs when inputs and outputs may change non-proportionally. Results: Theoretical results show that the new super-efficiency model is always feasible under the assumption of non-CRS. Also, numerical examples from the literature are provided to test the new super-efficiency approach. Conclusion: This study provides a non-radial measure of super-efficiency based on the ERM model to discriminate among the efficient DMUs resulting different efficiency scores greater than one. Unlike the traditional radial super-efficiency models, the proposed method is always feasible.
\end{abstract}

Key words: Data envelopment analysis, Decision Making Units (DMUs), super-efficiency, ranking efficient units, Enhanced Russell Measure (ERM)

\section{INTRODUCTION}

Data Envelopment Analysis (DEA) is a mathematical programming technique that can be used to distinguish between efficient and inefficient Decision Making Units (DMUs). However, the conventional DEA models lack the ability to rank the efficient DMUs. For this purpose, many models (called super-efficiency DEA models) have been proposed to identify the classification of efficient DMUs. The super-efficiency models can be applied in many areas such as industries, financial institutions; education and health care (Nahra et al., 2009). Andersen and Petersen (1993) developed the first radial super-efficiency model (AP model hereafter) for ranking the efficient DMUs by excluding the efficient DMU from the reference set of all the other DMUs in such a way that the efficiency scores for efficient DMUs can be greater than one. Then, many authors proposed various models for ranking the efficient DMUs. For more details see (Zhu, 2001; Tone, 2002; Chen, 2004; Li et al., 2007; Liu and Peng, 2008) among others. In some cases, the radial super-efficiency models can be infeasible. For example, see discussions in (Seiford and Zhu, 1999; Chen, 2005; Li et al., 2007). Due to the infeasibility of the super-efficiency model, ranking has been limited to the radial model under the assumption of Constant Returns to Scale (CRS).

In this study, we propose a super-efficiency model based upon the Enhanced Russell Measure (ERM) model developed by Pastor et al. (1999) for ranking the efficient DMUs. The ERM model is non-radial and deal with inputs/outputs individually, unlike the radial DEA models that the variations of inputs/outputs are proportional. In other words in ERM model the

Corresponding Author: Ali Ashrafi, Institute for Mathematical Research, Universiti Putra Malaysia, 43400 UPM SERDANG, Selangor, Malaysia Tel: +6017-2940140 Fax:+603-89437958 
inputs/outputs are allowed to decrease/increase at different rates. It is demonstrated that the proposed super-efficiency model is always feasible under both CRS and Variable Returns to Scale (VRS) assumptions. Then, we apply two numerical examples to test the new super-efficiency model.

\section{MATERIALS AND METHODS}

Enhanced Russell measure: Suppose there are n DMUs, where each $\operatorname{DMU}_{\mathrm{j}}(\mathrm{j}=1, \ldots, \mathrm{n})$ consumes $\mathrm{m}$ inputs $x_{i j}(i=1, \ldots, m)$ to generate s outputs $y_{r j}(r=1, \ldots, s)$. We assume that all inputs and outputs are positive. Vectors $x_{j}=\left(x_{1 j}, x_{2 j}, \ldots, x_{m j}\right)^{T}$ and $y_{j}=\left(y_{1 j}, y_{2 j}, \ldots, y_{s j}\right)^{T}$ represent input and output of $\mathrm{DMU}_{\mathrm{j}}$, respectively. We denote the $\mathrm{DMU}_{\mathrm{j}}$ by $\left(\mathrm{x}_{\mathrm{j}}, \mathrm{y}_{\mathrm{j}}\right)$. The production possibility set $\mathrm{P}_{\mathrm{C}}$ under the CRS assumption is defined as:

$$
P_{C}=\left\{(x, y) \mid x \geq \sum_{j=1}^{n} \lambda_{j} x_{j}, y \leq \sum_{j=1}^{n} \lambda_{j} y_{j}, \lambda_{j} \geq 0, j=1, \ldots, n\right\} .
$$

Assuming CRS, the non-radial Enhanced Russell Measure (ERM) model to measure the relative efficiency of $\mathrm{DMU}_{\mathrm{k}}(\mathrm{k}=1, \ldots, \mathrm{n})$, introduced by Pastor et al. (1999), is given as follows:

$$
\begin{aligned}
& \rho^{*}=\min \rho=\frac{1}{m} \sum_{\mathrm{i}=1}^{\mathrm{m}} \theta_{\mathrm{i}} / \frac{1}{\mathrm{~s}_{\mathrm{r}=1}^{\mathrm{s}} \varphi_{\mathrm{r}}} \\
& \text { s.t. } \theta_{\mathrm{i}} \mathrm{x}_{\mathrm{ik}} \geq \sum_{\mathrm{j}=1}^{\mathrm{n}} \lambda_{\mathrm{j}} \mathrm{x}_{\mathrm{ij}}, \quad \mathrm{i}=1, \ldots, \mathrm{m}, \\
& \varphi_{\mathrm{r}} \mathrm{y}_{\mathrm{rk}} \leq \sum_{\mathrm{j}=1}^{\mathrm{n}} \lambda_{\mathrm{j}} \mathrm{y}_{\mathrm{rj}}, \quad \mathrm{r}=1, \ldots, \mathrm{s}, \\
& \lambda_{\mathrm{j}} \geq 0,0 \leq \theta_{\mathrm{i}} \leq 1, \varphi_{\mathrm{r}} \geq 1, \\
& \mathrm{j}=1, \ldots, \mathrm{n}, \mathrm{i}=1, \ldots, \mathrm{m}, \mathrm{r}=1, \ldots, \mathrm{s},
\end{aligned}
$$

where, the numerator expresses the average efficiency of the inputs and the denominator expresses the average efficiency of the outputs. Therefore, the objective function can be interpreted as the ratio between the average efficiency of the inputs and the average efficiency of the outputs. From model (1), it holds $0<\rho \leq 1$. Note that the ERM model satisfies properties such as unit invariance and monotone decreasing for any increase in input usage or any decrease in output production.

Definition 1: (ERM-efficiency) A DMU $(k=1, \ldots, n)$ is ERM-efficient if and only if $\rho^{*}=1$.

This condition is equivalent to $\theta_{\mathrm{i}}^{*}=1,(\mathrm{i}=1, \ldots, \mathrm{m})$ and $\varphi_{\mathrm{r}}^{*}=1,(\mathrm{r}=1, \ldots, \mathrm{s})$ in any optimal solution.
ERM Super-efficiency: Suppose that $\mathrm{DMU}_{\mathrm{k}}=\left(\mathrm{x}_{\mathrm{k}}, \mathrm{y}_{\mathrm{k}}\right)$ is ERM-efficient, i.e. $\rho^{*}=1$. In an effort to evaluate the ranking of efficient DMUs, first we remove the $\mathrm{DMU}_{\mathrm{k}}$ from the reference set of model (1). Therefore the production possibility set for the remaining DMUs is as follows:

$$
P_{C}^{\prime}=\left\{(x, y) \mid x \geq \sum_{j=1 \neq k}^{n} \lambda_{j} x_{j}, y \leq \sum_{j=1 \neq k}^{n} \lambda_{j} y_{j}, \lambda_{j} \geq 0, j=1, \ldots, n, j \neq k\right\} .
$$

Based on the new production possibility set, model (1) needs to be modified because in order for the $\mathrm{DMU}_{\mathrm{k}}$ to reach the new frontier, we need to increase its inputs and decrease its outputs. For this purpose, the following model is introduced:

$$
\begin{aligned}
& \delta^{*}=\min \delta=\frac{1}{\mathrm{~m}} \sum_{\mathrm{i}=1}^{\mathrm{m}} \theta_{\mathrm{i}} / \frac{1}{\mathrm{~s}} \sum_{\mathrm{r}=1}^{\mathrm{s}} \varphi_{\mathrm{r}} \\
& \text { s.t. } \theta_{\mathrm{i}} \mathrm{x}_{\mathrm{ik}} \geq \sum_{\mathrm{j}=1, \neq \mathrm{k}}^{\mathrm{n}} \lambda_{\mathrm{j}} \mathrm{x}_{\mathrm{ij}}, \quad \mathrm{i}=1, \ldots, \mathrm{m}, \\
& \varphi_{\mathrm{r}} \mathrm{y}_{\mathrm{rk}} \leq \sum_{\mathrm{j}=1, \neq \mathrm{k}}^{\mathrm{n}} \lambda_{\mathrm{j}} \mathrm{y}_{\mathrm{rj}}, \quad \mathrm{r}=1, \ldots, \mathrm{s}, \\
& \lambda_{\mathrm{j}} \geq 0, \theta_{\mathrm{i}} \geq 1,0<\varphi_{\mathrm{r}} \leq 1, \\
& \mathrm{j}=1, \ldots, \mathrm{n}, \mathrm{j} \neq \mathrm{k}, \mathrm{i}=1, \ldots, \mathrm{m}, \mathrm{r}=1, \ldots, \mathrm{s} .
\end{aligned}
$$

Note that in this model, $\theta_{\mathrm{i}} \geq 1$ and $0<\phi_{\mathrm{r}} \leq 1$ instead of, $0 \leq \theta \leq 1$ and $\phi_{\mathrm{r}} \geq 1$. From the objective function, this is evident that $\delta \geq 1$.

It is remarkable that the model (2) is proposed under CRS assumption. The proposed model holds under the assumption of VRS by adding the convexity constraint, namely $\sum_{\mathrm{j}=1, \neq \mathrm{k}}^{\mathrm{n}} \lambda_{\mathrm{j}}=1$, into the model (2).

The model (2) is a nonlinear programming problem that can be converted into a linear programming problem by using the Cooper et al. (2007) transformation as follows:

$$
\begin{aligned}
\delta^{*}=\min & \frac{1}{m} \sum_{i=1}^{m} u_{i} \\
\text { s.t. } & \sum_{r=1}^{s} v_{r}=s, \\
& \sum_{j=1, \neq k}^{n} \alpha_{j} x_{i j} \leq u_{i} x_{i k}, \quad i=1, \ldots, m, \\
& \sum_{j=1, \neq k}^{n} \alpha_{j} y_{r j} \geq v_{r} y_{r k}, \quad r=1, \ldots, s, \\
& \alpha_{j} \geq 0, u_{i} \geq \beta, v_{r} \leq \beta, 0 \leq \beta \leq 1, \\
& j=1, \ldots, n, j \neq k, i=1, \ldots, m, r=1, \ldots, s,
\end{aligned}
$$

where, 
Am. J. Applied Sci., 8 (1): 92-96, 2011

$$
\begin{aligned}
& \beta^{-1}=\frac{1}{\mathrm{~s}} \sum_{\mathrm{r}=1}^{\mathrm{s}} \varphi_{\mathrm{r}}, \mathrm{u}_{\mathrm{i}}=\beta \theta_{\mathrm{i}}(\mathrm{i}=1, \ldots, \mathrm{m}), \\
& \mathrm{v}_{\mathrm{r}}=\beta \varphi_{\mathrm{r}}(\mathrm{r}=1, \ldots, \mathrm{s}), \text { and } \alpha_{\mathrm{j}}=\beta \lambda_{\mathrm{j}}(\mathrm{j}=1, \ldots, \mathrm{n}, \mathrm{j} \neq \mathrm{k}) .
\end{aligned}
$$

\section{RESULTS}

We demonstrate the characteristics of our model, theoretically by the following theorems.

Theorem 1: Under the assumption of CRS or VRS the ERM super-efficiency model is always feasible.

Proof: To demonstrate the feasibility of the model (2), we set:

$\theta_{\mathrm{i}} \mathrm{x}_{\mathrm{ik}}=\mathrm{x}_{\mathrm{ik}}+\mathrm{t}_{\mathrm{ik}}^{-}, \quad \mathrm{i}=1, \ldots, \mathrm{m}$,

$\varphi_{\mathrm{r}} \mathrm{y}_{\mathrm{rk}}=\mathrm{y}_{\mathrm{rk}}-\mathrm{t}_{\mathrm{rk}}^{+}, \quad \mathrm{r}=1, \ldots, \mathrm{s}$,

where, $\mathrm{t}_{\mathrm{ik}}^{-},(\mathrm{i}=1, \ldots, \mathrm{m})$ and $\mathrm{t}_{\mathrm{rk}}^{+},(\mathrm{r}=1, \ldots, \mathrm{s})$ are nonnegative variables. By substituting these values in the constraints of model (2), we have:

$$
\begin{array}{ll}
\mathrm{x}_{\mathrm{ik}}+\mathrm{t}_{\mathrm{ik}}^{-} \geq \sum_{\mathrm{j}=1, \neq \mathrm{k}}^{\mathrm{n}} \lambda_{\mathrm{j}} \mathrm{x}_{\mathrm{ij}}, & \mathrm{i}=1, \ldots, \mathrm{m}, \\
\mathrm{y}_{\mathrm{rk}}-\mathrm{t}_{\mathrm{rk}}^{+} \leq \sum_{\mathrm{j}=\mathrm{l}, \neq \mathrm{k}}^{\mathrm{n}} \lambda_{\mathrm{j}} \mathrm{y}_{\mathrm{rj}} & \mathrm{r}=1, \ldots, \mathrm{s} .
\end{array}
$$

For any non-negative set of $\hat{\lambda}_{j},(j=1, \ldots, n, j \neq k)$, we define:

$$
\begin{aligned}
& \hat{\mathrm{t}}_{\mathrm{ik}}^{-}=\max \left\{\mathrm{x}_{\mathrm{ik}}, \sum_{\mathrm{j}=1, \neq \mathrm{k}}^{\mathrm{n}} \hat{\lambda}_{\mathrm{j}} \mathrm{x}_{\mathrm{ij}}\right\}-\mathrm{x}_{\mathrm{ik}} \mathrm{i}=1, \ldots, \mathrm{m}, \\
& \hat{\mathrm{t}}_{\mathrm{rk}}^{+}=\mathrm{y}_{\mathrm{rk}}-\min \left\{\mathrm{y}_{\mathrm{rk}}, \sum_{\mathrm{j}=1, \neq \mathrm{k}}^{\mathrm{n}} \hat{\lambda}_{\mathrm{j}} \mathrm{y}_{\mathrm{rj}}\right\} \mathrm{r}=1, \ldots, \mathrm{s} .
\end{aligned}
$$

Thus, the set of

$$
\lambda_{\mathrm{j}}=\hat{\lambda}_{\mathrm{j}},(\mathrm{j}=1, \ldots, \mathrm{n}, \mathrm{j} \neq \mathrm{k}) ; \theta_{\mathrm{i}}=\left(\mathrm{x}_{\mathrm{ik}}+\hat{\mathrm{t}}_{\mathrm{ik}}^{-}\right) / \mathrm{x}_{\mathrm{ik}},(\mathrm{i}=1, \ldots, \mathrm{m})
$$

and $\varphi_{\mathrm{r}}=\left(\mathrm{y}_{\mathrm{rk}}-\hat{\mathrm{t}}_{\mathrm{rk}}^{+}\right) / \mathrm{y}_{\mathrm{rk}},(\mathrm{r}=1, \ldots, \mathrm{s})$ is a feasible solution for the ERM super-efficiency model. This remains true under the VRS assumption by adding $\sum_{\mathrm{j}=1, \neq \mathrm{k}}^{\mathrm{n}} \lambda_{\mathrm{j}}=1$, into the model (2).

Theorem 1 indicates that unlike the radial superefficiency DEA models, the ERM super-efficiency model is always feasible under the both CRS and VRS assumptions.

Theorem 2: Let $\left(a_{k}, b y_{k}\right)$ with $0<a \leq 1$ and $b \geq 1$ be a DMU with reduced inputs and enlarged outputs. Then $\delta^{*}$ from model (2) for $\left(a_{k}, b_{k}\right)$ is not less than that for $\left(x_{k}, y_{k}\right)$
Proof: Consider the ERM super-efficiency for $\left(\mathrm{ax}_{\mathrm{k}}\right.$, $\mathrm{by}_{\mathrm{k}}$ ) as follows:

$$
\begin{aligned}
& \delta^{*}=\min \delta=\frac{1}{\mathrm{~m}} \sum_{\mathrm{i}=1}^{\mathrm{m}} \theta_{\mathrm{i}} / \frac{1}{\mathrm{~s}_{\mathrm{r}=1}^{\mathrm{s}}} \varphi_{\mathrm{r}} \\
& \text { s.t. } \theta_{\mathrm{i}}\left(\mathrm{ax}_{\mathrm{ik}}\right) \geq \sum_{\mathrm{j}=1, \neq \mathrm{k}}^{\mathrm{n}} \lambda_{\mathrm{j}} \mathrm{x}_{\mathrm{ij}}, \quad \mathrm{i}=1, \ldots, \mathrm{m}, \\
& \varphi_{\mathrm{r}}\left(\mathrm{by}_{\mathrm{rk}}\right) \leq \sum_{\mathrm{j}=1, \mathrm{k}}^{\mathrm{n}} \lambda_{\mathrm{j}} \mathrm{y}_{\mathrm{rj}}, \quad \mathrm{r}=1, \ldots, \mathrm{s}, \\
& \lambda_{\mathrm{j}} \geq 0, \theta_{\mathrm{i}} \geq 1,0<\varphi_{\mathrm{r}} \leq 1, \\
& \mathrm{j}=1, \ldots, \mathrm{n}, \mathrm{j} \neq \mathrm{k}, \mathrm{i}=1, \ldots, \mathrm{m}, \mathrm{r}=1, \ldots, \mathrm{s} .
\end{aligned}
$$

Let $\mathrm{S}$ and $\hat{\mathrm{S}}$ be the solution spaces of the models (2) and (4), respectively. We show that $\hat{\mathrm{S}} \subseteq \mathrm{S}$, therefore, the super efficiency score of $\left(\mathrm{ax}_{\mathrm{k}}, \mathrm{by}_{\mathrm{k}}\right)$ is not less than the super-efficiency score of $\left(x_{k}, y_{k}\right)$. Suppose that $\left\{\hat{\lambda}_{j}, j=1, \ldots, n, j \neq k ; \hat{\theta}_{i}, i=1, \ldots, m ; \hat{\varphi}_{r}, r=1, \ldots, s\right\} \quad$ is $\quad$ a feasible solution for model (4), then we have:

$$
\begin{array}{ll}
\sum_{\mathrm{j}=1, \neq \mathrm{k}}^{\mathrm{n}} \hat{\lambda}_{\mathrm{j}} \mathrm{x}_{\mathrm{ij}} \leq \mathrm{a}\left(\hat{\theta}_{\mathrm{i}} \mathrm{x}_{\mathrm{ik}}\right) \leq \hat{\theta}_{\mathrm{i}} \mathrm{x}_{\mathrm{ik}}, & \mathrm{i}=1, \ldots, \mathrm{m}, \\
\sum_{\mathrm{j}=1, \neq \mathrm{k}}^{\mathrm{n}} \hat{\lambda}_{\mathrm{j}} \mathrm{y}_{\mathrm{rj}} \geq \mathrm{b}\left(\hat{\varphi}_{\mathrm{r}} \mathrm{y}_{\mathrm{rk}}\right) \geq \hat{\varphi}_{\mathrm{r}} \mathrm{y}_{\mathrm{rk}}, & \mathrm{r}=1, \ldots, \mathrm{s},
\end{array}
$$

which indicates that

$\left\{\hat{\lambda}_{j}, j=1, \ldots, n, j \neq k ; \hat{\theta}_{i}, i=1, \ldots, m ; \hat{\varphi}_{r}, r=1, \ldots, s\right\}$ is $\quad$ a

feasible solution to model (2). Therefore $\hat{S} \subseteq S$ and the proof is complete.

Relationship with the AP model: Andersen and Petersen (1993) developed the first radial superefficiency model for ranking the efficient DMUs by excluding the efficient DMU from the reference set of all the other DMUs to reach an efficiency score greater than or equal to one. The AP model is presented as follows:

$$
\begin{aligned}
& \theta^{*}=\min \theta-\varepsilon\left(\sum_{\mathrm{i}=1}^{m} s_{i}^{-}+\sum_{r=1}^{s} s_{r}^{+}\right) \\
& \text {s.t. } \sum_{j=1, \neq k}^{n} \mu_{j} x_{i j}+s_{i}^{-}=\theta x_{i k}, i=1, \ldots, m, \\
& \\
& \sum_{j=1, \neq k}^{n} \mu_{j} y_{r j}-s_{r}^{+}=y_{r k}, r=1, \ldots, s, \\
& \mu_{j}, s_{i}^{-}, s_{r}^{+} \geq 0 \\
& \\
& j=1, \ldots, n, j \neq k, i=1, \ldots, m, r=1, \ldots, s,
\end{aligned}
$$

where, $\varepsilon>0$ is a non-Archimedean infinitesimal constant. For an efficient DMU, $\theta^{*}$ is not less than one. 
Am. J. Applied Sci., 8 (1): 92-96, 2011

Table 1: Data and results from ERM super-efficiency and AP models

\begin{tabular}{llllllrllll}
\hline DMU & $\mathrm{I}_{1}$ & $\mathrm{I}_{2}$ & $\mathrm{I}_{3}$ & $\mathrm{I}_{4}$ & $\mathrm{O}_{1}$ & $\mathrm{O}_{2}$ & $\delta^{*}$ & Rank & $\theta^{*}$ & Rank \\
\hline 1 & 80 & 600 & 54 & 8 & 90 & 5 & 1.012 & 6 & 1.028 & 6 \\
2 & 65 & 200 & 97 & 1 & 58 & 1 & 1.708 & 2 & 2.417 \\
3 & 83 & 400 & 72 & 4 & 60 & 7 & 1.078 & 4 & 1.312 \\
4 & 40 & 1000 & 75 & 7 & 80 & 10 & 1.156 & 3 & 1.625 \\
5 & 52 & 600 & 20 & 3 & 72 & 8 & 1.799 & 1 & 2.403 & 2 \\
6 & 94 & 700 & 36 & 5 & 96 & 9 & 1.020 & 5 & 1.063 & 5 \\
\hline
\end{tabular}

Table 2: Data and results of ERM model and ERM super-efficiency model

\begin{tabular}{|c|c|c|c|c|c|c|c|c|c|}
\hline \multirow[b]{2}{*}{ DMU } & \multicolumn{3}{|l|}{ Inputs } & \multicolumn{3}{|c|}{ Outputs } & \multirow[b]{2}{*}{$\rho^{*}$} & \multirow[b]{2}{*}{$\delta^{*}$} & \multirow[b]{2}{*}{ Rank } \\
\hline & $\mathrm{x}_{1}$ & $\mathrm{x}_{2}$ & $\mathrm{x}_{3}$ & $\mathrm{y}_{1}$ & $\mathrm{y}_{2}$ & $\mathrm{y}_{3}$ & & & \\
\hline 1 & 0.950 & 0.700 & 0.155 & 0.190 & 0.521 & 0.293 & 1.000 & 1.033 & 7 \\
\hline 2 & 0.796 & 0.600 & 1.000 & 0.227 & 0.627 & 0.462 & 0.558 & & \\
\hline 3 & 0.798 & 0.750 & 0.513 & 0.228 & 0.970 & 0.261 & 0.533 & & \\
\hline 4 & 0.864 & 0.550 & 0.210 & 0.193 & 0.632 & 1.000 & 1.000 & 1.671 & 2 \\
\hline 5 & 0.815 & 0.850 & 0.268 & 0.233 & 0.722 & 0.246 & 0.507 & & \\
\hline 6 & 0.842 & 0.650 & 0.500 & 0.207 & 0.603 & 0.569 & 0.611 & & \\
\hline 7 & 0.719 & 0.600 & 0.350 & 0.182 & 0.900 & 0.716 & 1.000 & 1.114 & 4 \\
\hline 8 & 0.785 & 0.750 & 0.120 & 0.125 & 0.234 & 0.298 & 0.480 & & \\
\hline 9 & 0.476 & 0.600 & 0.135 & 0.080 & 0.364 & 0.244 & 0.530 & & \\
\hline 10 & 0.678 & 0.550 & 0.510 & 0.082 & 0.184 & 0.049 & 0.102 & & \\
\hline 11 & 0.711 & 1.000 & 0.305 & 0.212 & 0.318 & 0.403 & 0.466 & & \\
\hline 12 & 0.811 & 0.650 & 0.255 & 0.123 & 0.923 & 0.628 & 1.000 & 1.070 & 5 \\
\hline 13 & 0.659 & 0.850 & 0.340 & 0.176 & 0.645 & 0.261 & 0.494 & & \\
\hline 14 & 0.976 & 0.800 & 0.540 & 0.144 & 0.514 & 0.243 & 0.293 & & \\
\hline 15 & 0.685 & 0.950 & 0.450 & 1.000 & 0.262 & 0.098 & 1.000 & 3.834 & 1 \\
\hline 16 & 0.613 & 0.900 & 0.525 & 0.115 & 0.402 & 0.464 & 0.375 & & \\
\hline 17 & 1.000 & 0.600 & 0.205 & 0.090 & 1.000 & 0.161 & 1.000 & 1.174 & 3 \\
\hline 18 & 0.634 & 0.650 & 0.235 & 0.059 & 0.349 & 0.068 & 0.157 & & \\
\hline 19 & 0.372 & 0.700 & 0.238 & 0.039 & 0.190 & 0.111 & 0.190 & & \\
\hline 20 & 0.583 & 0.550 & 0.500 & 0.110 & 0.615 & 0.764 & 1.000 & 1.061 & 6 \\
\hline
\end{tabular}

The relationship between the ERM superefficiency model and the AP model is demonstrated by the following theorem.

Theorem 3: The super-efficiency score $\delta^{*}$ is not greater than the super-efficiency score $\theta^{*}$.

Proof: Suppose that $\left\{\mu_{\mathrm{j}}^{*}, \mathrm{j}=1, \ldots, \mathrm{n}, \mathrm{j} \neq \mathrm{k} ; \theta^{*}\right\}$ is an optimal solution of model (5). We define:

$$
\begin{aligned}
& \hat{\lambda}_{j}=\mu_{j}^{*}, j=1, \ldots, n, \\
& \hat{\theta}_{i}=\theta^{*}, i=1, \ldots, m \\
& \hat{\varphi}_{r}=1, r=1, \ldots, s
\end{aligned}
$$

Then $\left\{\hat{\lambda}_{\mathrm{j}}, \mathrm{j}=1, \ldots, \mathrm{n}, \mathrm{j} \neq \mathrm{k} ; \hat{\theta}_{\mathrm{i}}, \mathrm{i}=1, \ldots, \mathrm{m} ; \hat{\varphi}_{\mathrm{r}}, \mathrm{r}=1, \ldots, \mathrm{s}\right\}$ is a feasible solution for model (2). Therefore,

$$
\delta^{*} \leq \frac{\frac{1}{\mathrm{~m}} \sum_{\mathrm{i}=1}^{\mathrm{m}} \hat{\theta}_{\mathrm{i}}}{\frac{1}{\mathrm{~s}} \sum_{\mathrm{r}=1}^{\mathrm{s}} \hat{\varphi}_{\mathrm{r}}}=\frac{\frac{1}{\mathrm{~m}}\left(\mathrm{~m} \theta^{*}\right)}{\frac{1}{\mathrm{~s}}(\mathrm{~s})}=\theta^{*}
$$

\section{DISCUSSION}

In this section, two examples are provided to test the proposed super-efficiency model. First a numerical example is applied for comparing the new superefficiency model with AP model. Then an application of the ERM super-efficiency model for ranking the efficient DMUs, is shown by using an empirical example

A numerical example: Consider six efficient DMUs with four inputs $\left(\mathrm{I}_{1}, \mathrm{I}_{2}, \mathrm{I}_{3}\right.$ and $\left.\mathrm{I}_{4}\right)$ and two outputs $\left(\mathrm{O}_{1}\right.$ and $\mathrm{O}_{2}$ ) taken from Tofallis (1996). The data set is shown in the left hand side of Table 1 . The super-efficiency scores obtained by models (2) and (5) are displayed in columns $\delta^{*}$ and $\theta^{*}$ of Table 1 , respectively. According to Theorem 3, the super-efficiency score obtained by the ERM super-efficiency model becomes lower than that of the AP model. The ranking results of these two models, as reported in the right side of Table 1, are quite similar.

Empirical example: The proposed model is used to rank the efficient branches of 20 bank branches in Iran provided by Amirteimoori and Kordrostami (2005). The data set is presented in Table 2. Each bank is 
associated with three inputs: staff $\left(\mathrm{x}_{1}\right)$, computer terminals $\left(\mathrm{x}_{2}\right)$ and space $\left(\mathrm{x}_{3}\right)$ and three outputs: deposits $\left(\mathrm{y}_{1}\right)$, loans $\left(\mathrm{y}_{2}\right)$ and charges $\left(\mathrm{y}_{3}\right)$. Table 2 under the heading $\rho^{*}$ reports the ERM efficiency scores calculated by model (1), where there are seven fully efficient DMUs. Our goal is to rank these seven DMUs. The ERM super-efficiency scores and ranking of these seven efficient DMUs measured by model (2), are displayed in the far right columns of Table 2 under the heading $\delta^{*}$. Thus we have the top-ranked bank branch 15 followed by bank branches 4, 17, 7, 12, 20 and 1, respectively. Therefore, the new super-efficiency model can successfully rank the efficient DMUs.

\section{CONCLUSION}

This study proposed a super-efficiency model based on the Enhanced Russell Measure (ERM) model to rank the efficient DMUs in Data Envelopment Analysis (DEA). As an ERM model, the ERM superefficiency model is non-radial and appropriate for ranking the efficient DMUs when inputs and outputs may change non-proportionally. As a result, a complete ranking of efficient DMUs can be obtained by using the ERM super-efficiency model. We demonstrated that unlike the radial super-efficiency models, the proposed super-efficiency model is always feasible under both CRS and VRS assumptions. Further, the relationship between our model and the traditional radial measure of super-efficiency, i.e., the AP model, was described. Two numerical examples have been examined using the proposed super-efficiency model. It has been shown that the super-efficiency model can successfully differentiate among the efficient DMUs.

Recently, Chen et al. (2010) proposed a new measurement of efficiency based on the Russell measure that determines the best weight for each input (output). Application of Chen et al.'s model for ranking the efficient DMUs would be a future research subject

\section{REFERENCES}

Andersen, P. and N.C. Petersen, 1993. A procedure for ranking efficient units in data envelopment analysis. Manage. Sci., 39: 1261-1264. DOI: 10.1287/mnsc.39.10.1261

Amirteimoori, A. and S. Kordrostami, 2005. Efficient surfaces and an efficiency index in DEA: A constant returns to scale. Applied Math. Comput., 163: 683-691. DOI: 10.1016/j.amc.2004.04.009
Chen, Y., 2004. Ranking efficient units in DEA. Omega, 32: 213-219. DOI: 10.1016/j.omega.2003.11.001

Chen, Y., 2005. Measuring super-efficiency in DEA in the presence of infeasibility. Eur. J. Operat. Res., 161: 545-551. DOI: 10.1016/j.ejor.2003.08.060

Chen, T.H., C.P. Bao, C.M. Huang and I.C. Wang, 2010. Efficiency decomposition with enhancing russell measure in data envelopment analysis. Am. J. Applied Sci., 7: 438-441. DOI: 10.3844/ajassp.2010.438.441

Cooper, W.W., Z. Huang, S.X. Li, B.R. Parker and J.T. Pastor, 2007. Efficiency aggregation with enhanced russell measures in data envelopment analysis. Socio-Econ. Plann. Sci., 41: 1-21. DOI: 10.1016/j.seps.2006.03.001

Li, S., G.R. Jahanshahloo and M. Khodabakhshi, 2007. A super-efficiency model for ranking efficient units in data envelopment analysis. Applied Math. Computation, 184: 638-648. DOI: 10.1016/j.amc.2006.06.063

Liu, F.F. and H.H. Peng, 2008. Ranking of units on the DEA frontier with common weights. Comp. Operat. Res., 35: 1624-1637. DOI: 10.1016/j.cor.2006.09.006

Nahra, T.A., D. Mendez and J.A. Alexander, 2009. Employing super-efficiency analysis as an alternative to DEA: An application in outpatient substance abuse treatment. Eur. J. Operat. Res., 196: 1097-1106. DOI: 10.1016/j.ejor.2008.04.022

Pastor, J.T., J.L. Ruiz and I. Sirvent, 1999. An enhanced DEA Russell graph efficiency measure. Eur. J. Operat. Res., 115: 596-607. DOI: 10.1016/S0377-2217(98)00098-8

Seiford, L.M. and J. Zhu, 1999. Infeasibility of superefficiency data envelopment analysis models. INFOR, 37: 174-187.

Tone, K., 2002. A slacks-based measure of superefficiency in data envelopment analysis. Eur. J. Operat. Res. 143: 32-41. DOI: 10.1016/S03772217(01)00324-1

Tofallis, C., 1996. Improving discernment in DEA using profiling. Omega, 24: 361-364. DOI: 10.1016/0305-0483(95)00065-8

Zhu, J., 2001. Super-efficiency and DEA sensitivity analysis. Eur. J. Operat. Res., 129: 443-455. DOI: 10.1016/S0377-2217(99)00433-6 